\title{
Teaching opportunities during Covid-19
}

\author{
Juan Antonio Sala-Ramos \\ Hong Kong Tennis Association, Hong Kong.
}

\section{RESUMEN}

Without question, the current situation poses a challenge we have not seen before in the tennis industry. This article shares how the Hong Kong Tennis Association had been providing e-learning opportunities to its players during COVID-19 with the use of ICTs and how important it can be to implement an online curriculum in our tennis programs.
Key words: COVID-19, ICT use, online learning, innovation.

Received: 10 April 2021

Accepted: 20 May 2021

Corresponding author:

Juan Antonio Sala-Ramos. Email: juan.salaramos@tennishk.org

\section{INTRODUCTION}

According to the World Health Organization, COVID-19 was first detected in late 2019 in China and has since spread throughout the world in a short period to affect more than 10 million people (28 June 2020), including nearly half a million deaths. On 30 January 2020, the WHO declared the outbreak of COVID-19 disease as a global health emergency, and on 11 March, the disease was proclaimed a global pandemic.

An overwhelming majority of the world's enrolled students have experienced the temporary closing of school during the COVID-19 pandemic in an attempt to encourage social distancing and therefore decelerate the transmission of the virus (Viner et al., 2020)

We already know that tennis is one of the safest sports to practice during the pandemic due to the separation distance between players while playing against each other. Hong Kong, even though it is one of the countries that are better controlling the COVID-19 situation, the government has been very prudent. For several months, tennis was not allowed, so players did not have the opportunity to keep practicing tennis and keep learning concepts.

To keep the players engaged and provide continuous education, the Hong Kong Tennis Association decided to create several educational virtual rooms using the Google Classroom platform. Within the organization, the NA has different programs organized by age groups and levels. Each head coach is responsible for creating content with his coaches' team and tailoring the content to its players' needs.

\section{ONLINE LEARNING}

Online learning can be termed a tool that can make the teaching-learning process more student-centered, innovative, and even more flexible. Online learning is defined as "learning experiences in synchronous or asynchronous environments using different devices (e.g., mobile phones, laptops...) with internet access.
In these environments, students can be anywhere (independent) to learn and interact with instructors and other students" (Singh \& Thurman, 2019).

According to Liguori \& Winkler (2020), innovative solutions by institutions can only help us deal with this pandemic. This is precisely what the Hong Kong Tennis Association is trying with the implementation of an online curriculum for their tennis players.

\section{THE CLASSROOM}

Each classroom targets for the different age groups and levels inside the organization. On figure 1, you can observe how it looks the classrooms in the platform.

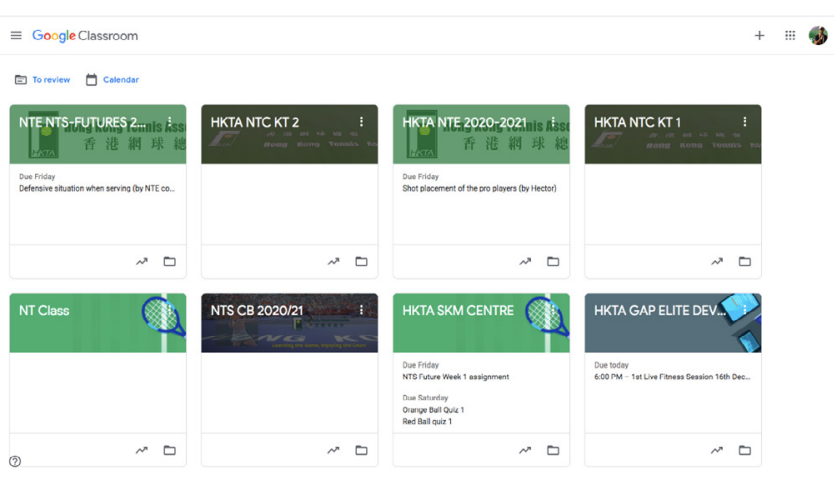

Figure 1. A general overview of the classrooms.

You can appreciate in Figure 2 how it looks like a week in the player's calendar.

A typical week of a player will mostly have at least one assignment of each topic. 


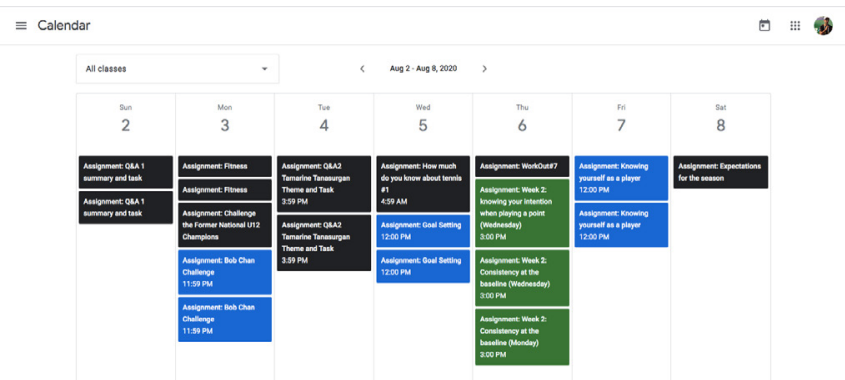

Figure 2. A general view of the weekly player's calendar.

There are different topics and content within the classroom that the Hong Kong Tennis Association Coaching team considers essential and can be taught online. That knowledge will be useful for the player once we can get back to the tennis courts again.

\section{Tactical:}

In this section, we teach the players various tactical aspects that they should take into consideration. We usually attach a theoretical material for the players to read first, followed by a visual explanation on video where the players can get the idea more efficiently. After that, we ask them to complete a quiz to test if they understood the basic concepts. To finish, we deliver an assignment more completed that evaluates all the knowledge acquired. After that, we correct the works and put them a final grade with individual feedback.

\section{Fitness:}

It is essential for the player's mental health, especially the young ones, to keep physically active; that's why we provided two fitness sessions per week for all our different age groups. Figure 3 shows an example of a fitness session done with some of our players. We worked on various aspects as injury prevention, strength, and conditioning. Sessions are run via the Zoom Platform by our fitness coaches.

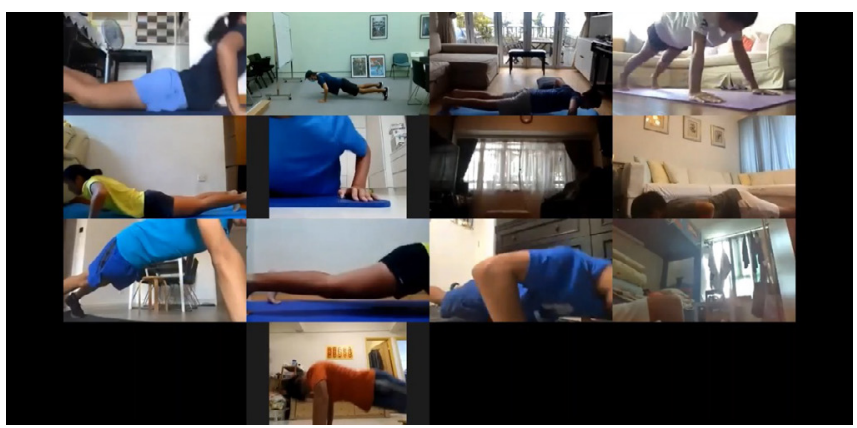

Figure 3: Players during a fitness session.

\section{Mental training:}

As we all know, tennis's mental aspect is essential and is a crucial factor while competing. Each Heach Coach updates his classroom two times per week with assignments about mental topics, as the example, you can observe in figure 4.

Assignments as: How to deal with nerves; How do you train mentally?; Improve focus, self-control.
Tennis, a mental game?

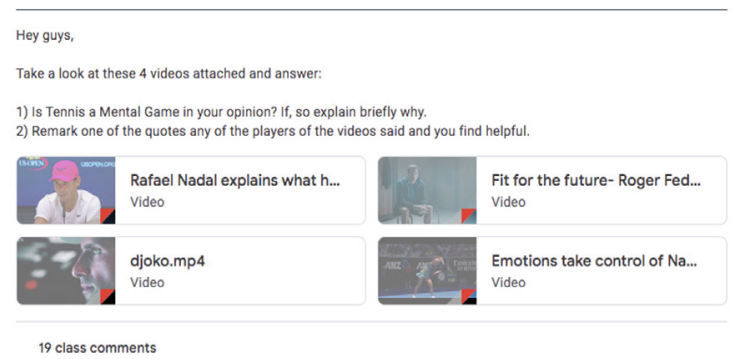

Figure 4 : An example of a mental assignment for the players.

\section{Tennis Trivia:}

In this section, we test the player's knowledge and teach them about tennis questions about tennis's history, tennis words meaning, or rules in specific tournaments from ATF or ITF.

\section{Q \& A with Professional Athletes:}

Every week the Hong Kong Tennis Association brings a professional athlete who will be answering all the questions that the players from the national association have via the Zoom platform.

Some examples of professional athletes who participated in the $Q \& A$ are:

- Tamarine Tanasurgan. "How to use respect to maximize yourself as a player."

- Sofia Arvidsson. "Don't stop improving."

- Matwe Middelkoop. "Never give up".

- Nick Matthew. "Hard work pays off."

\section{Competitions:}

To keep players motivated during the lockdown, we created an online competition called "Stay Fit Battle."

Zoom platform holds the online competition, having one of the coaches responsible for acting as a referee of the match, determining who wins, and passing to the next round.

Each round has a different test for the players.

In the first round, we checked which player could do more frame touches (hand-eye coordination). Each player has three attempts to get as many frames touches as possible in a row.

In the second round, we tested how many burpees' repetitions the player could do in 3minutes, assessing at the same time their fitness level.

The Semifinal was a knowledge test about some topics and concepts we have worked on in the classroom before, observing if the players retain the new knowledge learned. And for the final, we did a competition to see who puts an overgrip faster than the other and checking their skills.

All the players enjoyed this online competition. After completing it, they asked for the second edition immediately, which tells us we are going in the right direction and showing us that online education can be fun and competitive if choosing the right way. 


\section{Challenges:}

A fun way to test our players' skills and, at the same time, boost our social media channels while we give prizes from our sponsors to the three players with a higher score.

Challenges as "spot where is the ball" or "guess how many balls are there on the basket "were some examples of challenges we did to engage our tennis community.

\section{POSITIVE EFFECTS WITH THE USE OF ICT}

- They make it possible to learn in a more attractive way than traditional methods.

- The players' understanding and interest are favored by having very varied resources such as audiovisual material and multimedia tools that reinforce the players' knowledge.

- It is a great help for those introverted players to communicate with the other players, going from being a mere receiver to an active participant in the classroom dynamics.

- They help create autonomy for the players by having different channels to search for information and promote self-learning.

- It eliminates the barriers of space and time between the coach and the player, allowing the learning experience to continue outside the tennis court.

\section{CONCLUSION}

With the use of technologies nowadays, we should consider using e-learning platforms to provide and off-court education to our players. As they could be used for wet weather sessions, working with injured players, or just as a follow-up of what we train daily on the court and give a more dedicated service to our clients.
We have realized that there are not just opposing sides during this challenging time, but also positive ones. Due to the COVID-19 situation, we provide the opportunity to keep the tennis community engages, learning, and which is more important, mentally healthy and active.

In conclusion, tennis innovation should be something that is not just a consequence of the impact that COVID-19 is having on the tennis industry. Still, as an opportunity to improve our tennis programs' service by implementing an online curriculum and taking advantage of the rapid developments in technology that have made distance education easy (McBrien et al., 2009).

\section{REFERENCES}

Liguori, E. W., y Winkler, C. (2020). De lo offline a lo online: Challenges and opportunities for entrepreneurship education following the COVID-19 pandemic. Entrepreneurship Education and Pedagogy. https://journals.sagepub.com/doi/10.1177/2515127420916738

McBrien, J. L., Cheng, R., \& Jones, P. (2009). Espacios virtuales: El empleo de un aula online sincrónica para facilitar la participación de los estudiantes en el aprendizaje online. The International Review of Research in Open and Distributed Learning, 10(3), 1-17.

Singh, V., \& Thurman, A. (2019). De cuántas maneras podemos definir el aprendizaje en línea? Una revisión bibliográfica sistemática de las definiciones del aprendizaje en línea (19882018). American Journal of Distance Education, 33(4), 289-306. https://www.tandfonline.com/doi/abs/10.1080/08923647.2019.166308

Viner, R. M., Russell, S. J., Croker, H., Packer, J., Ward, J., Stansfield, C., Mytton, O., Bonell, C. \& Booy, R. (2020). Cierre de escuelas y prácticas de gestión durante los brotes de Coronavirus incluyendo COVID-19: A rapid systematic review. The Lancet Child \& Adolescent Health, 4(3), 397-404.https://www.thelancet.com/action/showPdf?pii=S2352$4642 \% 2820 \% 2930095-X$

OMS. Cuadro de mando de la enfermedad por coronavirus (COVID-19). Disponible en línea: https://covid19.who.int/ (consultado el 28 de junio de 2020).

OMS. Anuncia que el brote de COVID-19 es una pandemia. Disponible en línea: http://www.euro.who.int/en/health-topics/health-emergencies/ coronavirus-covid-19/news/news/2020/3/who-announces-covid-19outbreak-a-pandemic (consultado el 10 de mayo de 2020).

You are free to Share - copy and redistribute the material in any medium or format - and Adapt the content - remix, transform, and build upon the material for any purpose, even commercially under the following terms:

Attribution: You must give appropriate credit, provide a link to the license, and indicate if changes were made. You may do so in any reasonable manner, but not in any way that suggests the licensor endorses you or your use. 